\title{
Splenic marginal zone lymphoma: a case report and literature review
}

\author{
Shiyu Zhang ${ }^{1,2,3,4}$, Zefeng Xuan ${ }^{1,2,3,4}$, Liang Zhang ${ }^{1,2,3,4}$, Jiahua Lu ${ }^{1,2,3,4}$, Penghong Song ${ }^{1,2,3,4^{*}}$ and \\ Shusen Zheng ${ }^{1,2,3,4^{*}}$
}

\begin{abstract}
Background: Splenic marginal zone lymphoma (SMZL) is a rare non-Hodgkin lymphoma, and much little is known about its clinical characteristics and management strategies. Here we present a case of SMZL and review relevant literature to provide a better recognition of this disease entity.

Case presentation: A 49-year-old Chinese female was admitted to our hospital with complaints of abdominal distension and acid reflux. Physical examinations and imaging investigations suggested the presence of splenomegaly. Laboratory workups revealed mildly reduced white blood cell count otherwise was not remarkable. The patient underwent splenectomy. Histological examination combined with immunohistochemical analysis of the resected spleen confirmed the diagnosis of SMZL. The patient recovered uneventfully during follow-ups.

Conclusions: Due to the rarity and unspecific clinical features, SMZL is extremely challenging to be diagnosed preoperatively. Patients with SMZL are generally associated with favorable prognosis. Combining the staging characteristics of non-Hodgkin's lymphoma and splenic primary lymphoma may assist in clinical staging management of SMZL.
\end{abstract}

Keywords: Splenic marginal zone lymphoma, Management, Staging, Case report

\section{Background}

Lymphoma is a malignant tumor originating from the lymphatic hematopoietic system. According to the different cell sources, it is divided into non-Hodgkin lymphoma (NHL) and Hodgkin lymphoma (HL). Primary splenic lymphoma is a rare type of malignant lymphoma, which involves only the spleen and splenic hilar lymph nodes. However, splenic marginal zone lymphoma (SMZL) is even rarer.

SMZL represents a rare chronic B lymphocyte proliferative disease, which only accounts for about $1-2 \%$ of nonHodgkin's lymphoma [1]. The mean age of SMZL onset is about 65 years. There was no significant difference between men and women. About 25\% of patients with early SMZL

\footnotetext{
*Correspondence: songpenghong@zju.edu.cn; shusenzheng@zju.edu.cn 'The First Affiliated Hospital, Zhejiang University School of Medicine, Division of Hepatobiliary and Pancreatic Surgery, Department of Surgery, Zhejiang Province, China

Full list of author information is available at the end of the article
}

have no significant special discomfort; some people might only show the upper abdominal discomfort, such as abdominal pain and distention; and other patients may be accompanied by splenomegaly, emaciation, fatigue, weight loss, or other manifestations.

The cell origin of SMZL remains not fully clear; some scholars believe that it originates from memory B lymphocytes in the marginal zone of secondary lymphoid follicles [2]. The pathogenesis of the disease is still in the process of exploration. Many studies believe that its pathogenesis may be closely related to $7 q$ distortion [3]. Although it is an indolent lymphoma, about 10\% of patients can be converted to diffuse large B cell lymphoma [4], and if the patient has B symptoms, it will lead to the deterioration of the condition. Overall, the prognosis of SMZL is better than other types of lymphoma. If the patients show no obvious hypersplenism or disease progression, the median survival time of the disease may be more than 10 years $[5,6]$. 
Due to the rarity of this disease entity, little was known about its diagnosis and treatment. At present, the treatment of SMZL is relatively limited. If the patient has no obvious hypersplenism or disease progression, long-term follow-up is recommended firstly. General treatments include surgical treatment, radiation therapy, and systemic chemotherapy. For most patients, surgery is an effective way to both diagnosis and treatment of SMZL, and postoperative adjuvant chemotherapy can effectively prolong the survival rate.

At present, the current staging system for the SMZL is completely exploiting from the clinical experience of NHL. Due to the involvement of the spleen, SMZL was clearly classified as stage III NHL according to the staging system for the NHL. It is well recognized that patients with stage III NHL were associated with a dismal prognosis, with a 5-year survival of only $50 \%$. By stark contrast, the SMZL was fairly described as a relatively biologically indolent tumor, despite the nature of NHL, and usually portended a favorable prognosis. As such, the implementation of the staging system of NHL for SMZL may seem not reasonable. Given this background, we herein reported a case of SMZL and meanwhile reviewed the existing literature as well as our center experiences to propose a clinical staging system of SMZL, which may potentially assist in the management of this uncommon entity.

\section{Case presentation}

A 49-year-old Chinese female was presented to a local hospital with complaints of occasional abdominal distension and acid reflux of 1-month duration. The patient had no weight loss, anemia, or fever and denied any family history of cancer. The medical history of the patient was negative. Ultrasonography (US) and computed tomography $(\mathrm{CT})$ revealed splenomegaly. A tentative diagnosis of blood system diseases was made, and then the patient underwent a bone marrow biopsy, which suggested that granulocytes were normal in proportion, and no obvious atypical cells were found. Although repeated biopsy was suggested, the patient refused and was referred to our hospital. On admission, physical examination revealed that the abdomen of the patient was soft and the spleen can be touched under the left costal arch. Laboratory tests showed white blood cell count $3 \times 10^{9} / \mathrm{L}$, hemoglobin (HB) $125 \mathrm{~g} / \mathrm{L}$, and platelet count $151 \times 10^{9} / \mathrm{L}$. The liver function and coagulation function were within normal limits. US indicated that the spleen was $5.7 \mathrm{~cm}$ in thickness, with smooth contour, uniform, and meticulous echo of the spleen parenchyma. Enhanced CT (Fig. 1) was performed and suggested splenomegaly (maximum diameter $23 \mathrm{~cm}$ ), without swollen lymph nodes in the abdomen.

In order to make a definite diagnosis, the patient underwent splenectomy. During the operation, we found that the spleen is obviously enlarged, and the specimen of the resected spleen was roughly dark reddish (Fig. 2). The final pathological examination showed that both number and size of the splenic white pulp were increased, and small lymphocytes proliferate in the nodules (Fig. 3). The involvement of the splenic hilar lymph nodes was also noted. Immunohistochemistry was positive for Ki67, Bcl2, CD43, CD79a, and CD20 (Fig. 4). Eventually, the patient was diagnosed with SMZL.

The postoperative courses were uneventful. The patient's white blood cell count increased to $8.1 \times 10^{9} / \mathrm{L}$, and the platelet count increased to $465 \times 10^{9} / \mathrm{L}$. During 12 months of follow-ups, the patient showed no signs of recurrence or spread.

\section{Discussion and conclusions}

The spleen represents the largest solid immune organ of the body. It contains numerous lymphocytes and macrophages and serves as the center of cellular immunity and humoral immunity [7, 8]. Located between the white pulp and the red pulp of the spleen, the marginal region is approximately $100 \mu \mathrm{m}$ in width and is the main anatomical channel for the peripheral lymphocytes to enter the lymphatic system of the spleen. Functionally, the marginal region

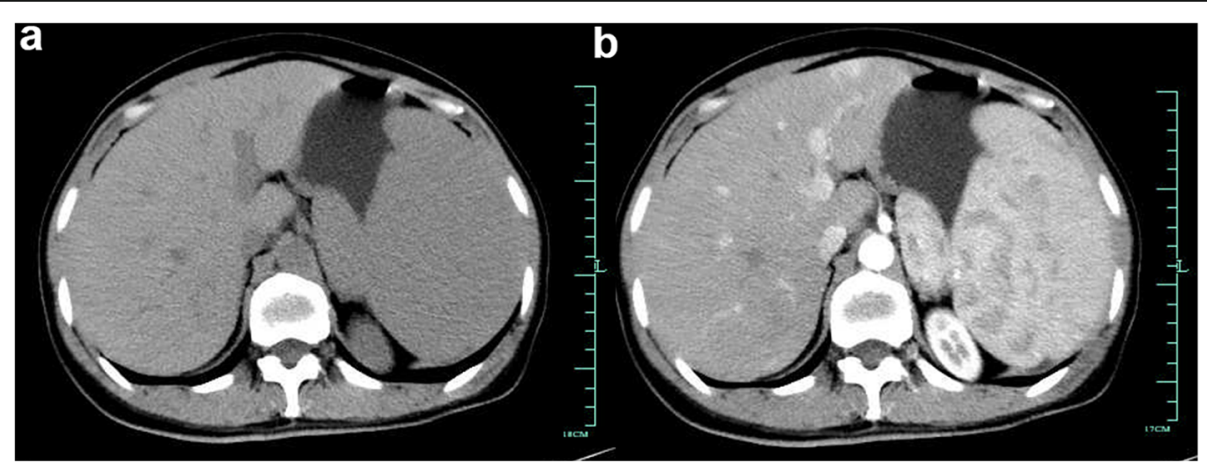

Fig. 1 Abdominal enhanced computed tomography (CT) images. The images showed the presence of splenomegaly (a), without significant enhancement (b) 


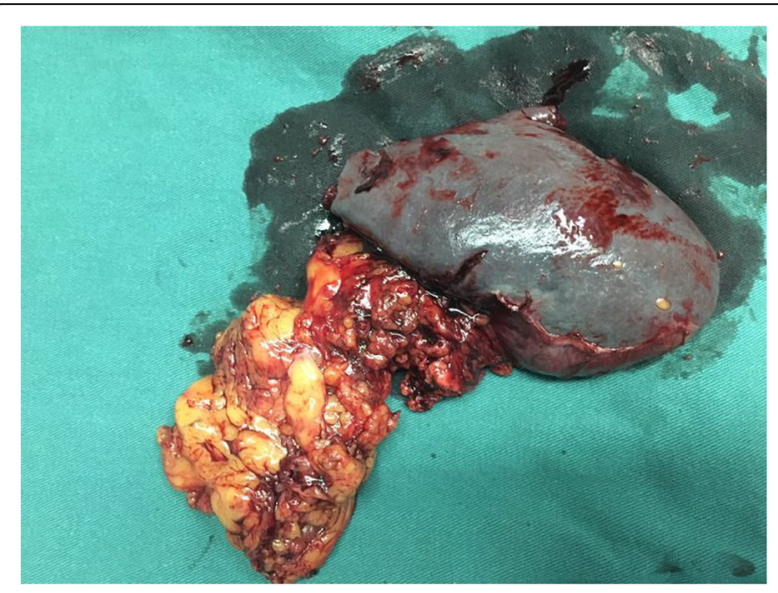

Fig. 2 Macroscopic examination of the postoperative specimen. The resected spleen measured $22 \times 13 \times 5 \mathrm{~cm}$ in size

of the spleen provides a platform for the recognition of antigens and activation of immune reactions [9].

Due to the rarity of SMZL, much little was known about its pathogenesis. NOTCH gene mutation $[10,11]$ and the deletion of 7q31-7q32 [12] were previously suggested to be involved in the development and progression of SMZL. In addition, patients with SMZL were frequently diagnosed as co-infected with hepatitis C virus (HCV) $[13,14]$. Nonetheless, these data should be interpreted cautiously because of the limited numbers of study subjects. In this case, the patient did not have $\mathrm{HBV} / \mathrm{HCV}$ infection, and the previous history was not remarkable.

Splenomegaly is the most typical symptom of SMZL, and some patients present with decreased appetite, fever, night sweats, and sudden weight loss. US is widely used in clinical practice, and the performance of SMZL is usually low or anechoic [15]. CT mainly shows splenomegaly, decreased lesion density on plain scan, and mild to moderate enhancement on enhanced scan [16]. PET/ CT shows increased splenic uptake of ${ }^{18} \mathrm{~F}-\mathrm{FDG}$, which is higher than the liver. Indeed, Rini et al. reported that
PET/CT had a $100 \%$ sensitivity to lymphoma of the spleen, compared with that of $57 \%$ for conventional CT scans [17]. However, because of the high price and radiation of $\mathrm{PET} / \mathrm{CT}$, it is not routinely recommended as the first choice in the clinical practice $[15,18]$. Due to unspecific imaging features, diagnostic splenectomy is still the preferred diagnostic method. Splenic histology is characterized by small lymphocyte infiltration with nodular hyperplasia. It is also suggested to use spleen biopsy to preoperatively diagnose SMZL regarding the advantages of reducing the risks of post-splenectomy complications typical of intraperitoneal hemorrhage and infection [19].

Due to the rarity of SMZL and its unspecific clinical manifestation, until now, there is still no uniform diagnostic standard. In 2008, Matutes et al. proposed the minimum diagnostic criteria for SMZL [17], which were based on spleen biopsy results and CLL immunophenotype score. However, the clinical classification of SMZL has yet been inconsistent. SMZL is a type of non-Hodgkin lymphoma (NHL) and therefore should be staged according to NHL criteria. According to the NHL criteria (staging system), when the tumor cells invade the spleen, its staging would be classified as at least stage III NHL; stage III is usually associated with a dismal prognosis and the 5 -year survival time is only about $50 \%$. However, SMZL is a relatively indolent lymphoma and had a favorable prognosis. As such, it may seem inappropriate to apply NHL standards for staging SMZL. On the other hand, SMZL is also a type of primary splenic lymphoma, and therefore, its clinical staging complies to Ahmann's staging criteria, which is widely used to primary splenic lymphoma irrespective of NHL. Therefore, we improved Ahmann's staging by taking different sites of lymphoma into consideration. But this is just our initial idea and still needs further confirmation. In our own staging standard (see Table 1 for details), SMZL is divided into 3 phases, according to different parts of tumor cell invasion. When lymphoma is limited to the spleen (stage I), the patients may have a favorable prognosis.

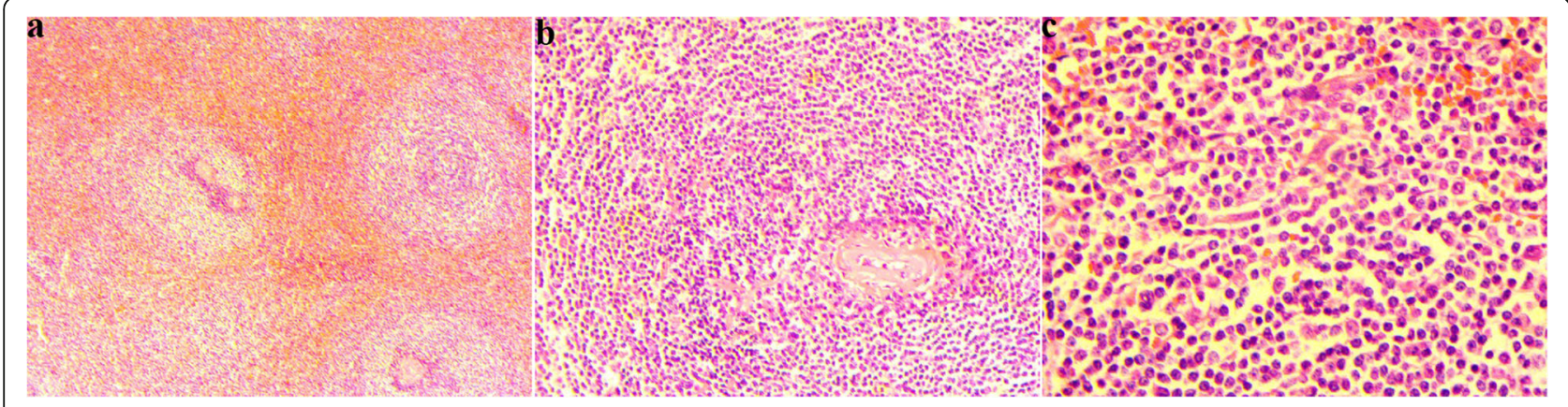

Fig. 3 Histopathological analysis of the surgical specimen. The tumor showed nodular growth pattern (hematoxylin and eosin (H\&E), $\times 40)(\mathbf{a})$ The white pulp of the spleen was significantly enlarged, where a large number of infiltrating tumor cells were observed. And the tumor cells were small and round in size $(\mathrm{H} \& \mathrm{E} ; \mathbf{b} \times 100, \mathbf{c} \times 200)$ 


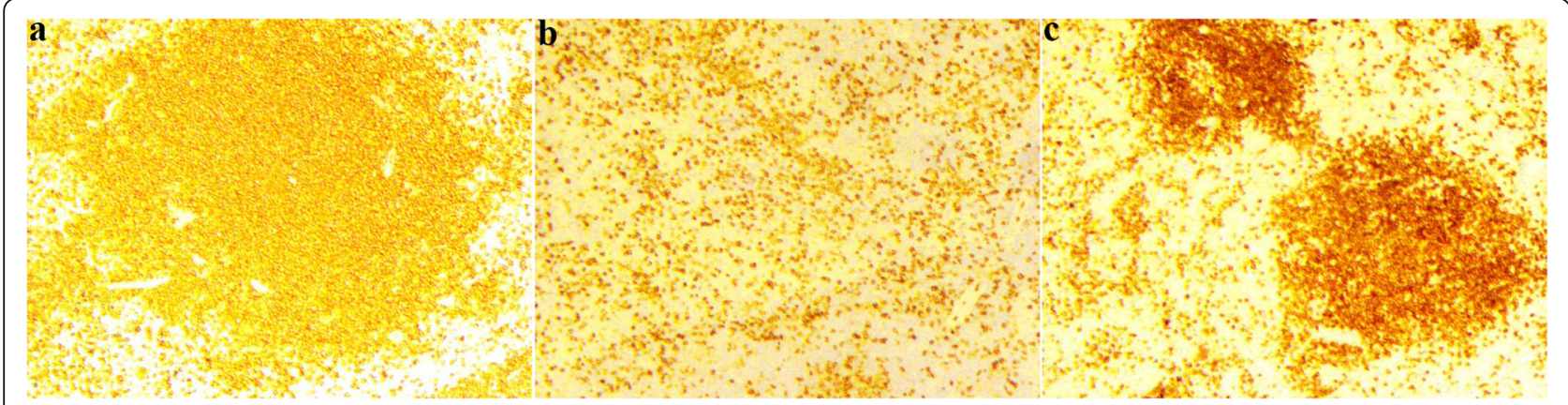

Fig. 4 Immunohistochemical examinations of the surgical specimen. Immunohistochemical staining revealed that tumor cells were strongly positive for CD20 (a), CD43 (b), and CD79a (c) (magnification, $\times 100$ )

Given the paucity of SMZL, no consensus of treatments can be reached. For asymptomatic patients, conservative treatment is recommended and close follow-up should be conducted about every 3-6 months. The follow-up examinations should include ultrasound, blood routine, and so on [20]. If a progressive change in the patient's condition is found during follow-up (such as hypersplenism and B symptoms), then hospitalization will be recommended [21]. For HCV-positive SMZL patients with no obvious surgical indications (such as hypersplenism), interferon alone or combined with ribavirin for anti-HCV therapy may be considered as an effective option [22]. Antiviral therapy could achieve the clearance of serum HCV RNA and, at the same time, contribute to the remission of SMZL. Rossotti et al. reported that after 16 weeks of antiviral therapy for SMZL patients with coexistent HCV infection, the serum viral load of $\mathrm{HCV}$ in these patients became undetectable and the size of the spleen normalized [23]. For HCVnegative SMZL patients who have obvious splenomegaly, splenectomy is still the first choice for treatment. It has been reported that splenectomy could significantly prolong the patient's survival, especially for those with preoperative thrombocytopenia [24]. Splenectomy could achieve the purposes of getting a definitive diagnosis, reducing the tumor burden and relieving thrombocytopenia-associated symptoms. Additionally, SMZL patients who received splenectomy as the first-line therapy were reported to have a median survival time of 8.25 years, with a 5 -year overall survival rate of $84 \%$ [25]. In another study, Olszewski et al.

Table 1 The staging criteria for SMZL

\begin{tabular}{ll}
\hline Stage I & $\begin{array}{l}\text { Tumors were confined to the spleen only; no metastatic } \\
\text { lesions were found in the splenic lymph nodes and } \\
\text { outside the spleen. }\end{array}$ \\
Stage II & $\begin{array}{l}\text { The tumor involved in the splenic lymph nodes but no } \\
\text { other parts of the lymph nodes or the external organs } \\
\text { of the lymphatic system. }\end{array}$ \\
Stage III & $\begin{array}{l}\text { Lymph node involvement outside the spleen or } \\
\text { extra-lymphatic organs and their associated lymph nodes } \\
\text { (liver and bone marrow). }\end{array}$
\end{tabular}

If the patient has fever, night sweats, and clinical manifestations of weight loss in the past 3 months, it is classified as class B; otherwise, it is class A reported that the disease-free survival for SMZL patients undergoing splenectomy generally exceeded 5 years [26]. However, it should be noted that severe infection after splenectomy, also known as overwhelming post-splenectomy infection (OPSI), is highly lethal, with an estimated mortality rate of $5 \%[27,28]$. The majority of OPSI is caused by encapsulated bacteria, typically of the pneumococcus, meningococcal $\mathrm{C}$ pathogens and hemophilus influenza B [29]. To prevent the development of OPSI, vaccination against encapsulated bacteria is mandatory within 2 weeks before or after splenectomy and then once a year for 5 consecutive years [29]. While for patients who cannot tolerate surgery or experience tumor recurrence after surgery, chemotherapy should be considered. A retrospective study by Riccioni et al. reported that following cladribine treatment $\left(5 \mathrm{mg} / \mathrm{m}^{2} /\right.$ week, 6 courses), the partial remission rate and complete remission $(\mathrm{CR})$ rate of SMZL patients could achieve $60 \%$ and $20 \%$, respectively [30]. Iannitto et al. used pentostatin $\left(4 \mathrm{mg} / \mathrm{m}^{2} /\right.$ every 2 weeks) to treat SMZL for 6 to 10 weeks, and the overall remission rate (ORR) was about 68\% [31]. Recently, with the advent of the anti-CD20 monoclonal antibody (mainly rituximab), the paradigm of systemic therapy for SMZL has changed, and rituximab-based therapy has become an effective alternative to splenectomy [32]. The standard rituximab monotherapy should include induction and maintenance phases. Rituximab is given at the standard dose $\left(375 \mathrm{mg} / \mathrm{m}^{2} /\right.$ week $)$ once per week for 6 weeks during the induction phase. Then, in the maintenance phase, rituximab is given at the standard dose (once every 2 months) for 1-2 years [33, 34]. Kalpadakis et al. reported that treatment with rituximab monotherapy could result in a 5-year overall survival rate of 92\% [33]. In addition, for SMZL patients with constitutional symptoms, rituximab combined with chemotherapy may be considered. Brown et al. reported that after combined treatment strategy (fludarabine combined with rituximab), the ORR was up to 85\% [35]. Furthermore, splenic irradiation has been suggested as an effective treatment option for SMZL patients who respond poorly to the systemic therapy. Oliveira et al. reported that 


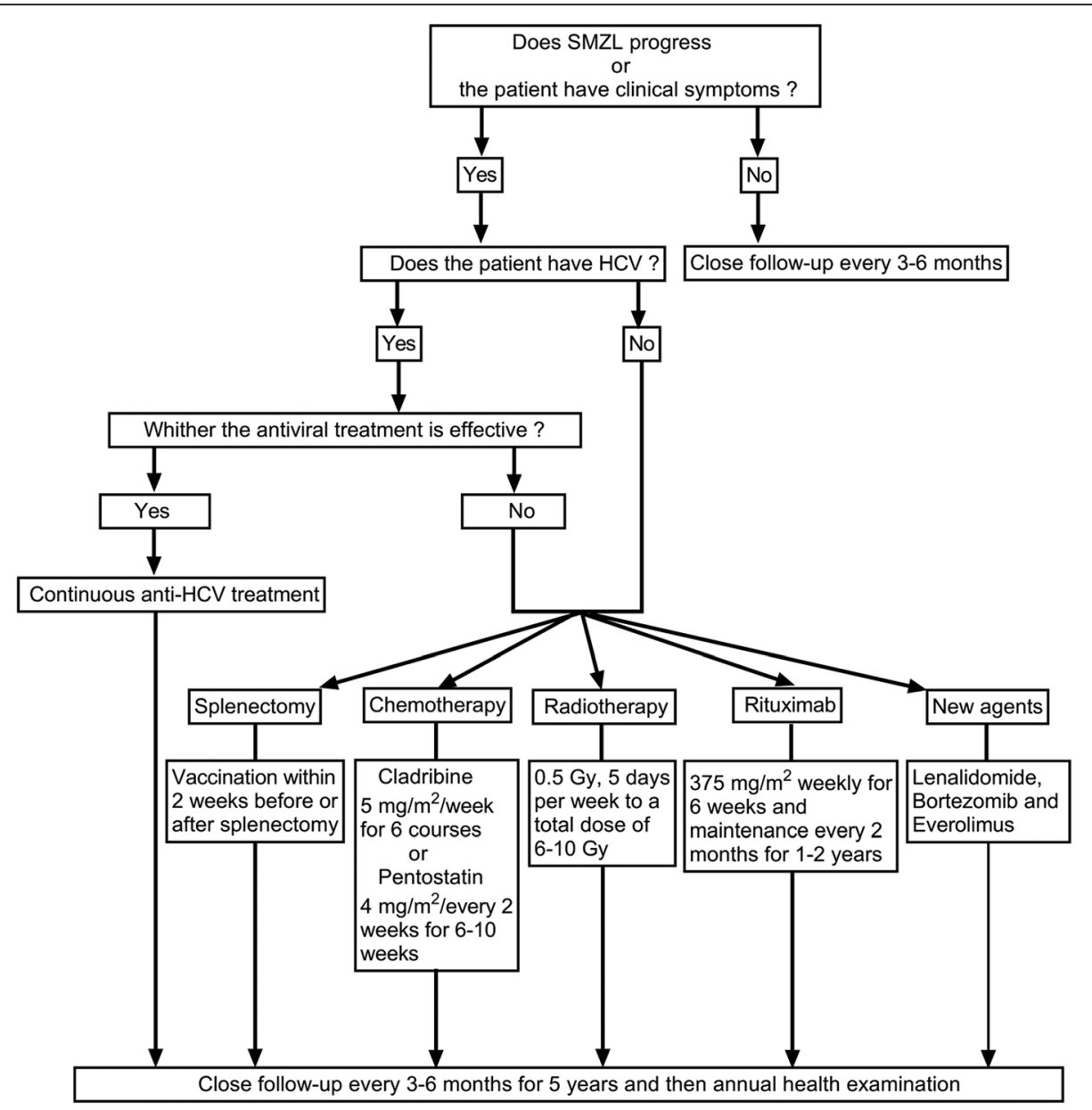

Fig. 5 Flow diagram depicting the management of patients with SMZL. A brief summary of the management strategy for the SMZL

Table 2 Summary of the demographic characteristics of patients with SMZL in our center

\begin{tabular}{lll}
\hline Variables & Number of cases & Percentage \\
\hline Gender & 4 & \\
Male & 12 & 25.0 \\
Female & & 75.0 \\
Age & 4 & \\
$0-49$ & 11 & 25.0 \\
$50-70$ & 1 & 68.75 \\
$>70$ & & 6.25 \\
Main symptoms & 3 & \\
No obvious symptoms & 4 & 18.75 \\
Abdominal discomfort & 2 & 25.0 \\
Fever & 2 & 12.5 \\
Weight loss & 3 & 12.5 \\
Changes in blood routine results & 2 & 18.75 \\
Fatigue & & 12.5 \\
\hline
\end{tabular}

splenic radiotherapy ( 1.5 Gy, 5 days a week for 3 weeks) could effectively diminish the volume of the enlarged spleen [36]. It has also been reported that the low-dose spleen radiotherapy regimen $(0.5 \mathrm{~Gy}, 5$ days per week to a total dose of 6-10 Gy) could provide effective palliation for SMZL without excessive toxicity [37, 38]. And, more remarkable, repeated irradiation seems to be safe for those patients with no durable response [38]. More recently, novel agents for SMZL have been designed and tested in several clinical studies, including lenalidomide, bortezomib, and everolimus [32]. Although these studies are just in infancy, the results seem promising. In Fig. 5, we summarize the specific treatment for SMZL.

Table 3 Summary of the size of the surgically resected spleen for patients with SMZL

\begin{tabular}{ll}
\hline Spleen size & Centimeters \\
\hline Min & $18 \times 13 \times 5$ \\
Max & $40 \times 20 \times 15$ \\
Average & $24.9 \times 15.8 \times 8.6$ \\
\hline
\end{tabular}


Table 4 The immunohistochemical staining results of SMZL

\begin{tabular}{ll}
\hline Immunohistochemistry & Proportion \\
\hline CD20 (+) & $16 / 16(100 \%)$ \\
CD79a (+) & $11 / 16(68.75 \%)$ \\
CD43 (+) & $9 / 16(56.25 \%)$ \\
\hline
\end{tabular}

In order to know more about SMZL, we collected information of 16 patients who failed to be diagnosed before operation from the First Affiliated Hospital of Zhejiang University since 2010. Most patients were between 50 and 70 years old, which was consistent with literature reports. Patients with SMZL presented with abdominal discomfort, fever, and other non-specific manifestations (Table 2). Almost all patients presented with splenomegaly, and the largest case even reached 40 $\times 20 \times 15 \mathrm{~cm}$ (Table 3). In terms of immunohistochemistry, almost all tumor tissues showed positive for CD20 and CD79a (Table 4).

To sum up, SMZL is a low-grade malignant non-Hodgkin lymphoma. Due to lack of typical clinical manifestations, it is necessary to combine US, CT, PET/CT, and other imaging examinations, laboratory examinations, bone marrow biopsy, immunohistochemistry, histopathology, and other comprehensive examinations for the diagnosis of SMZL. We merged the staging of non-Hodgkin's lymphoma and primary splenic lymphoma and proposed a staging for SMZL, but further confirmation is needed in the future.

\section{Abbreviations}

CT: Computed tomography; CR: Complete remission; HB: Hemoglobin; HCV: Hepatitis C virus; HL: Hodgkin lymphoma; NHL: Non-Hodgkin lymphoma; OPSI: Overwhelming post-splenectomy infection; ORR: Objective response rate; PET: Positron emission tomography; SMZL: Splenic marginal zone lymphoma; US: Ultrasonography

\section{Acknowledgements}

Not applicable.

\section{Authors' contributions}

Zhang SY reviewed the relevant literature and participated in the drafting of the manuscript. Xuan ZF participated in the revision of the manuscript. Lu JH and Zhang $L$ participated in the information collection. Song PH and Zheng SS are co-corresponding authors. All authors read and approved the revised manuscript.

\section{Funding}

No specific funding was obtained for this study.

\section{Availability of data and materials}

Not applicable.

\section{Ethics approval and consent to participate}

Not applicable as this is a case report, not a clinical study.

\section{Consent for publication}

Written informed consent for the publication of patient clinical details and clinical images was obtained from the patient.

\section{Competing interests}

The authors declared there were no competing interests.

\section{Author details}

${ }^{1}$ The First Affiliated Hospital, Zhejiang University School of Medicine, Division of Hepatobiliary and Pancreatic Surgery, Department of Surgery, Zhejiang Province, China. ${ }^{2} \mathrm{NHC}$ Key Laboratory of Combined Multi-organ Transplantation, Zhejiang Province, China. ${ }^{3}$ Key Laboratory of the diagnosis and treatment of organ Transplantation, Research Unit of Collaborative Diagnosis and Treatment For Hepatobiliary and Pancreatic Cancer, Chinese Academy of Medical Sciences, Beijing Province, China. ${ }^{4}$ Key Laboratory of Organ Transplantation, Research Center for Diagnosis and Treatment of Hepatobiliary Diseases, Zhejiang Province 310003, Hangzhou, China.

Received: 28 April 2020 Accepted: 16 September 2020

Published online: 01 October 2020

\section{References}

1. Vallisa D, Bernuzzi P, Arcaini L, Sacchi S, Callea V, Marasca R, Lazzaro A, Trabacchi E, Anselmi E, Arcari AL, et al. Role of anti-hepatitis C virus (HCV) treatment in HCV-related, low-grade, B-cell, non-Hodgkin's lymphoma: a multicenter Italian experience. J Clin Oncol. 2005;23:468-73.

2. Algara $P$, Mateo MS, Sanchez-Beato $M$, Mollejo M, Navas IC, Romero L, Solé F, Salido M, Florensa L, Martínez P, et al. Analysis of the lgV(H) somatic mutations in splenic marginal zone lymphoma defines a group of unmutated cases with frequent $7 q$ deletion and adverse clinical course. Blood. 2002;99:1299-304.

3. Mateo M, Mollejo M, Villuendas R, Algara P, Sanchez-Beato M, Martínez P, Piris MA. 7q31-32 allelic loss is a frequent finding in splenic marginal zone lymphoma. Am J Pathol. 1999;154:1583-9.

4. Thieblemont $C$, Felman $P$, Berger F, Dumontet $C$, Arnaud $P$, Hequet $O$, Arcache J, Callet-Bauchu E, Salles G, Coiffier B. Treatment of splenic marginal zone B-cell lymphoma: an analysis of 81 patients. Clin Lymphoma. 2002;3:41-7.

5. Thieblemont C, Felman P, Callet-Bauchu E, Traverse-Glehen A, Salles G, Berger F, Coiffier B. Splenic marginal-zone lymphoma: a distinct clinical and pathological entity. Lancet Oncol. 2003;4:95-103.

6. Chacón Jl, Mollejo M, Muñoz E, Algara P, Mateo M, Lopez L, Andrade J, Carbonero IG, Martínez B, Piris MA, Cruz MA. Splenic marginal zone lymphoma: clinical characteristics and prognostic factors in a series of 60 patients. Blood. 2002;100:1648-54.

7. Mebius RE, Kraal G. Structure and function of the spleen. Nat Rev Immunol. 2005;5:606-16.

8. Cesta MF. Normal structure, function, and histology of the spleen. Toxicol Pathol. 2006;34:455-65.

9. Kraemer BB, Osborne BM, Butler JJ. Primary splenic presentation of malignant lymphoma and related disorders. A study of 49 cases. Cancer. 1984:54:1606-19.

10. Spina $V$, Rossi D. Molecular pathogenesis of splenic and nodal marginal zone lymphoma. Best Pract Res Clin Haematol. 2017;30:5-12.

11. Rossi D, Trifonov V, Fangazio M, Bruscaggin A, Rasi S, Spina V, Monti S, Vaisitti T, Arruga F, Famà R, et al. The coding genome of splenic marginal zone lymphoma: activation of $\mathrm{NOTCH} 2$ and other pathways regulating marginal zone development. J Exp Med. 2012;209:1537-51.

12. Ruiz-Ballesteros E, Mollejo M, Mateo M, Algara P, Martínez P, Piris MA. MicroRNA losses in the frequently deleted region of $7 q$ in SMZL. Leukemia. 2007;21:2547-9.

13. Wu L, Tian $\mathrm{C}$, Zhang $Y Z$. Progress on treatment of splenic marginal zone lymphoma-review. Zhongguo Shi Yan Xue Ye Xue Za Zhi. 2017;25:600-3.

14. Szynglarewicz B, Matkowski R, Smorag Z, Forgacz J, Pudelko M, Kornafel J. Hepatitis $C$ virus infection and locally advanced splenic marginal zone lymphoma. Pathol Oncol Res. 2007;13:382-4.

15. Dachman AH, Buck JL, Krishnan J, Aguilera NS, Buetow PC. Primary nonHodgkin's splenic lymphoma. Clin Radiol. 1998:53:137-42.

16. de Jong PA, van Ufford HM, Baarslag HJ, de Haas MJ, Wittebol SH, Quekel $L G$, de Klerk JM. CT and 18F-FDG PET for noninvasive detection of splenic involvement in patients with malignant lymphoma. AJR Am J Roentgenol. 2009;192:745-53.

17. Rini JN, Leonidas JC, Tomas MB, Palestro CJ. 18F-FDG PET versus CT for evaluating the spleen during initial staging of lymphoma. J Nucl Med. 2003; 44:1072-4.

18. Lee JD, Park CH, Griffith J, Vernick J. Gallium-67 scintiscan in the diagnosis of primary splenic non-Hodgkin's lymphoma after the treatment of Hodgkin's disease. J Nucl Med. 1992;33:1183-5. 
19. Gobbi PG, Grignani GE, Pozzetti U, Bertoloni D, Pieresca C, Montagna G, Ascari E. Primary splenic lymphoma: does it exist? Haematologica. 1994;79: 286-93

20. Arcaini L, Lazzarino M, Colombo N, Burcheri S, Boveri E, Paulli M, Morra E, Gambacorta M, Cortelazzo S, Tucci A, et al. Splenic marginal zone lymphoma: a prognostic model for clinical use. Blood. 2006;107:4643-9.

21. Matutes E, Oscier D, Montalban C, Berger F, Callet-Bauchu E, Dogan A, Felman P, Franco V, lannitto E, Mollejo M, et al. Splenic marginal zone lymphoma proposals for a revision of diagnostic, staging and therapeutic criteria. Leukemia. 2008;22:487-95.

22. Arcaini $L$, Vallisa $D$, Rattotti $S$, Ferretti $W$, Ferreri AJM, Bernuzzi $P$, Merli M, Varettoni M, Chiappella A, Ambrosetti A, et al. Antiviral treatment in patients with indolent B-cell lymphomas associated with HCV infection: a study of the Fondazione Italiana Linfomi. Ann Oncol. 2014;25:1404-10.

23. Rossotti R, Travi G, Pazzi A, Baiguera C, Morra E, Puoti M. Rapid clearance of HCV-related splenic marginal zone lymphoma under an interferon-free, NS3/NS4A inhibitor-based treatment. A case report. J Hepatol. 2015;62:234-7.

24. Morel P, Dupriez B, Gosselin B, Fenaux P, Estienne MH, Facon T, Jouet JP, Bauters $F$. Role of early splenectomy in malignant lymphomas with prominent splenic involvement (primary lymphomas of the spleen). A study of 59 cases. Cancer. 1993;71:207-15.

25. Olszewski AJ, Ali S. Comparative outcomes of rituximab-based systemic therapy and splenectomy in splenic marginal zone lymphoma. Ann Hematol. 2014;93:449-58.

26. Thieblemont C, Davi F, Noguera M-E, Brière J, Bertoni F, Zucca E, TraverseGlehen A, Felman P, Berger F, Salles G, Coiffier B. Splenic marginal zone lymphoma: current knowledge and future directions. Oncology (Williston Park, NY). 2012;26:194-202.

27. Lenglet J, Traullé C, Mounier N, Benet C, Munoz-Bongrand N, Amorin S, Noguera $M-E$, Traverse-Glehen A, Ffrench $M$, Baseggio L, et al. Long-term follow-up analysis of 100 patients with splenic marginal zone lymphoma treated with splenectomy as first-line treatment. Leukemia Lymphoma. 2014:55:1854-60

28. Xing KH, Kahlon A, Skinnider BF, Connors JM, Gascoyne RD, Sehn LH, Savage KJ, Slack GW, Shenkier TN, Klasa R, et al. Outcomes in splenic marginal zone lymphoma: analysis of 107 patients treated in British Columbia. Br J Haematol. 2015;169:520-7.

29. Stockinger Z, Grabo D, Benov A, Tien H, Seery J, Humphries A. Blunt Abdominal Trauma, Splenectomy, and Post-Splenectomy Vaccination. Mil Med. 2018;183:98-100

30. Riccioni R, Caracciolo F, Galimberti S, Cecconi N, Petrini M. Low dose 2-CdA schedule activity in splenic marginal zone lymphomas. Hematol Oncol. 2003;21:163-8.

31. Iannitto E, Minardi V, Calvaruso G, Ammatuna E, Florena AM, Mulè A, Tripodo C, Quintini G, Abbadessa V. Deoxycoformycin (pentostatin) in the treatment of splenic marginal zone lymphoma (SMZL) with or without villous lymphocytes. Eur J Haematol. 2005;75:130-5.

32. Kalpadakis C, Pangalis GA, Vassilakopoulos TP, Sachanas S, Angelopoulou MK. Treatment of splenic marginal zone lymphoma: should splenectomy be abandoned? Leukemia Lymphoma. 2014;55:1463-70.

33. Kalpadakis C, Pangalis GA, Angelopoulou MK, Sachanas S, Kontopidou FN, Yiakoumis X, Kokoris SI, Dimitriadou EM, Dimopoulou MN, Moschogiannis $M$, et al. Treatment of splenic marginal zone lymphoma with rituximab monotherapy: progress report and comparison with splenectomy. Oncologist. 2013;18:190-7.

34. Arcaini L, Rossi D, Paulli M. Splenic marginal zone lymphoma: from genetics to management. Blood. 2016;127:2072-81.

35. Brown JR, Friedberg JW, Feng Y, Scofield S, Phillips K, Dal Cin P, Joyce R, Takvorian RW, Fisher DC, Fisher Rl, et al. A phase 2 study of concurrent fludarabine and rituximab for the treatment of marginal zone lymphomas. $\mathrm{Br} J$ Haematol. 2009:145:741-8.

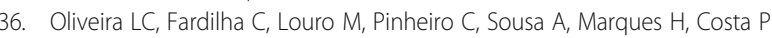
Palliative splenic irradiation for symptomatic splenomegaly in non-Hodgkin lymphoma. Ecancermedicalscience. 2018;12:887.

37. de la Pinta C, Fernández Lizarbe E, Montero Luis Á, Domínguez Rullán JA, Sancho García S. Treatment of symptomatic splenomegaly with low doses of radiotherapy: retrospective analysis and review of the literature. Tech Innov Patient Support Radiat Oncol. 2017;3-4:23-9.
38. Lavrenkov K, Krepel-Volsky S, Levi I, Ariad S. Low dose palliative radiotherapy for splenomegaly in hematologic disorders. Leukemia Lymphoma. 2012;53: $430-4$.

\section{Publisher's Note}

Springer Nature remains neutral with regard to jurisdictional claims in published maps and institutional affiliations.
Ready to submit your research? Choose BMC and benefit from:

- fast, convenient online submission

- thorough peer review by experienced researchers in your field

- rapid publication on acceptance

- support for research data, including large and complex data types

- gold Open Access which fosters wider collaboration and increased citations

- maximum visibility for your research: over $100 \mathrm{M}$ website views per year

At $\mathrm{BMC}$, research is always in progress.

Learn more biomedcentral.com/submissions 